\title{
The Tail of the Tiger: Experiences and perceptions of unemployment and inactivity in Donegal
}

\author{
Ian Shuttleworth
}

School of Geography. Queen's University of Belfast, Northern Ireland

Rob Kitchin

National University of Ireland, Maynooth

Peter Shirlow

School of Environmental Studies, University of Ulster

John McDonagh

National University of Ireland, Galway

\begin{abstract}
The experiences and perceptions of registered and 'hidden' unemployed people in Donegal are explored through an examination of survey data collected from 620 respondents between May and August 1997. This data set, consisting of both quantitative and qualitative information, is valuable because it explores unemployment and possible solutions from unemployed people's perspectives, and also investigates 'hidden' unemployment. It also provides some insights into social exclusion and the extent to which the 'Celtic Tiger' has benefited all parts of Irish society. Analyses are restricted to the quantitative aspects of the dataset and the discussion is divided into three main themes: labour market histories and experiences of unemployment; education and training; and perceptions of the labour market. In the last section of the paper the various findings are drawn together and summary recommendations are made concerning the actions that local agencies, as opposed to central Government, might undertake in order to tackle the causes and consequences of unemployment.
\end{abstract}

Key index words: unemployment, social exclusion, Donegal.

\section{Introduction}

The landscape of European rural areas is changing. Agriculture is no longer dominant in most regions of the EU. Some rural areas are experiencing increased levels of in-migration while others are suffering from increasing levels of population decline. The sustainability of the Irish rural economy and community is intrinsically linked to a mix of occupations, services and infrastructure. The Irish rural economy faces a number of well documented problems including lack of employment opportunities, unemployment, low incomes, poverty, inadequate levels of amenity and service provision, environmental decay, under utilisation/over utilisation of productive resources and absolute population decline (see NESC Report No. 97, 1994). Many of these problems are interrelated as, for example, an area with poor service provision generally experiences population out-migration.

terms of sustainability, the European Commission in its seminal paper, The Future of Rural Society (1988) laid down a strategic policy thrust for the sustainable development of rural areas. The delivery of sustainable development, however, ultimately depends on the capacity of human resources in the rural areas concerned. Any limitations with respect to human resources are likely to affect adversely the competitiveness of rural areas and retard 
the full exploitation of local potentials to the detriment of the quality of life and the sustainability of rural communities (McDonagh, 2000).

Unemployment and under-employment are key causes of poverty. In particular, those denied access to waged labour have to rely on a reduced household income provided through the welfare system. Moreover, as Curtin et al. (1996) note, rural unemployment is experienced differently to urban unemployment both in terms of its causes and consequences. For example, some commentators stress the role of geographical peripherality in maintaining and reproducing unemployment and others point to institutional changes which act to disadvantage more rural locations (e.g. Leyshon and Thrift, 1997). It seems likely that there is an interplay between these sets of factors so that some likely important macro-causes of unemployment include the restructuring of rural economies, changes in farm production and the centralisation of service provision. At the micro level, problems of training, transport, accessibility, and service provision may be key factors in reproducing unemployment in many areas (Dawes, 1993; Murphy, 1996; Shuttleworth et al., 1996). These factors mean that rural unemployment often remains high, despite other economic developments, and is resistant to attempts to reduce it. It is therefore important to learn more about experiences of unemployment in rural contexts so as to formulate appropriate policies.

The inability of industrial and welfare-based strategies to reduce unemployment and under-employment, and to promote social inclusion, sits in stark contrast to the significant growth in employment, wage levels and consumption patterns which characterise Ireland at present. At the national level, significant growth in wealth, productivity and output indicates the significance of a process of economic enlargement and wealth creation. Indeed only recently the International Institute of Management Development ranked Ireland eleventh in its league table of the world's most competitive economies - a position which placed it ahead of Japan and Britain (Irish Times, April 22nd 1998). Quite clearly this growth in economic status, over the past ten years, has been an economic success story. The main facts, familiar by now, still cause astonishment. Between 1994-1997 the Irish economy grew at an average rate of more than seven percent per annum. Moreover, whilst a decade ago Irish incomes were less than two-thirds of British incomes, in 1998, on one measure, they surpassed them by three percent. The globalisation and Europeanisation of the Irish economy has been important in wealth creation. As has been asserted in the pages of The Economist:

"If any country lends substance to the cliche that the global economy is an opportunity not a threat, it is Ireland" (Economist, 22nd May, 1998).

The achievements noted above cannot easily be dismissed, despite reservations over statistical fudges, subsidies from Europe and tax dodges for multinationals (Shirlow, 1995; 1996).

However, the benefits of the emergent 'Celtic Tiger' economy in terms of wealth distribution and job creation throughout Ireland remains questionable given the argument that such advantages are not evenly spread across social class and regional boundaries. Indeed the United Nation's Human Development Report (1998) indicated that Ireland now has the highest levels of (income based) social polarisation within the European Union, that the number of children living in poverty has increased two-fold since 1971 and that the gap between the economic status of men and women is worse than in any other OECD country. It can be argued that economic growth has reproduced a new form of 'place prosperity', a process within which the benefits of industrial and service sector enlargement is most 
noticeable within large towns and cities such as Dublin, Cork, Limerick and Galway. This evident growth in 'place prosperity' can be illustrated by reference to Dublin. Between 1994 1999 there was a 231 percent increase in second-hand house prices, a 27 percent growth in new cars sales in Dublin between 1995-1997, and a growth in real wages in Dublin of 17.6 percent between 1991 and 1997 (Irish Independent, 24th July 1999, and data supplied by Department of Finance, 1998). Similar trends are evident in Cork, Galway and Limerick.

However, predominantly rural counties have performed less well than the national average in terms of significant improvements in socio-economic well-being. In relation to job creation between 1987-1996 only six counties (Cork, Dublin, Limerick and Galway, Waterford and Meath) had a net increase in employment of over two percent. It has also been estimated that around 71 percent of new full-time jobs created between 1991-1997 were located within the same six counties (data supplied by Department of Finance, 1997).

The case study area, Donegal, because of its geographical position in north-western Ireland, is widely recognised as being peripheral. This peripherality is recognised not only in geographical terms but also to a degree in social, political and particularly economic terms. Donegal's peripherality is seen to be a particular drawback for the location of industry and the subsequent access requirement to central European markets. Changes in the rural economy of Donegal during the 1990s, particularly the dwindling role of traditional dependence on agriculture and fishing, have a significant impact not only in terms of agricultural restructuring but more so in the ability of rural Donegal to attract international investment. Coupled with this inability to attract investment is the continued outflow of younger people leaving behind an older less skilled workforce. The largest urban centre in Donegal, Letterkenny (over 10,000 people and the main economic and industrial area) is a case in point. Located within Letterkenny is an Institute of Technology with a good range of courses in IT yet the Donegal area has no big IT business. This leads to graduates from the Institute of Technology having to migrate to other counties to find suitable employment. There are also a number of other smaller centres including Buncrana (over 3000 people), Donegal town $(2000+)$ and Bundoran $(1700)$ but in general the region is characterised by a sparse rural population with a population density of 27 per sq. $\mathrm{km}$ - Ireland has 52 per sq. $\mathrm{km}$; Dublin 1147 per sq. $\mathrm{km}$ (CSO, 1996). Further, contained within this region is a large part of the Gaeltacht (Irish speaking area) with its own unique set of problems of integrating and promoting development (industrial, social, economic etc.) while maintaining the indigenous culture and Irish language. Donegal's location therefore ensures that its suffers from the classic problem of providing infrastructure and services to a geographically dispersed population.

The National Economic and Social Forum (1997) identified groups most at risk of poverty in rural areas. These included unemployed people, women, people with a disability, older people, migrants, lone parents, Gaeltacht communities, fishermen and farmers on small holdings. Within these groups unemployment was seen as one of the major factors causing poverty and while on a national basis unemployment has been reduced the long-term unemployment associated with the remoter rural areas still remains problematic.

Donegal is a useful example to illustrate these themes of rural unemployment and regional economic differentials. In general terms, the labour market of Donegal is characterised by high rates of unemployment (some 25 percent of the labour force in 1991), out-migration, and relatively high proportions of young people aged under fifteen years. Some indications of problems in the local labour market are given by indications that the 
population at work between 1971 and 1991 fell by some 14 percentage points, the numbers of unemployed grew by some 55 percentage points over the same period (Donegal County Enterprise Board, 1996). This suggests that more jobs are needed and that employment creation in the Donegal economy has not been sufficient to reduce unemployment. Sectorally, recent years have seen significant restructuring of the economy. In common with the State as a whole, Donegal has lost agricultural, forestry and fishing employment but has seen an increase in the proportion of manufacturing, service and administrative employment. Despite this, the local economy was marginally more reliant on agricultural employment than the rest of the State in 1991 and had slightly lower rates of service employment.

Employment growth has been a significant feature of the Irish economy in the $1990 \mathrm{~s}$. However, some counties, such as Donegal have performed less well, and do not appear to have shared in the economic miracle of the 'Celtic Tiger'. Evidence for the poor economic performance of Donegal relative to the other 25 counties of the State is apparent in data provided by the Department of Finance (1997) on socio-economic trends 1993-96. Donegal ranks $26^{\text {th }}$ in terms of employment growth, $26^{\text {th }}$ in unemployment decrease, $24^{\text {th }}$ in new car registrations, and $20^{\text {th }}$ in growth in tourism revenues. Employment policy (particularly that of the IDA) has to date focused on creating jobs and encouraging multi-national investment. This policy has been successful in dealing with chronic unemployment rates. However, this policy has also failed to reproduce and/or retain the range of skills, professions and services needed in rural areas and thereby has contributed to the decline of rural areas and to the human resource deficit which now exists. MacGréil (1999) argues that this laissez faire policy has consolidated the growth of strong population centres while simultaneously undermining vulnerable rural areas. This suggests that there are significant structural problems in local economies like that of Donegal which mean that high unemployment is unlikely to be quickly reduced.

The paper therefore has two main themes. Firstly, it looks at the experience of unemployment in Donegal in terms of the macro and micro-causes of unemployment, alluded to earlier, from the perspective of unemployed people themselves. It thus provides a 'bottomup' view of the labour market in contrast to 'top-down' approaches based on quantitative analyses of large-scale datasets. Attention is also paid to the subject of 'hidden unemployment' (Dawes, 1993). This occurs where people are not registered as official, 'visible' unemployed but are economically inactive, seeking work although not registered as claiming unemployment benefit, or are otherwise withdrawn from the labour market. Secondly, it considers unemployment within the context of the 'Celtic Tiger' phenomenon (especially in terms of uneven growth), and examines the experiences of one region, and some groups of people, who might be assumed to have had difficulties in benefiting from economic growth.

\section{The Setting}

Rural development in Ireland has shown a distinct lack of commitment to policies and operational programmes that promote equitable regional development. The deployment of new production technologies, partly in order to make the major agricultural commodities more competitive, greatly increased productivity per farmer, per hectare and per person engaged in agriculture throughout the EU. Not surprisingly, large labour surpluses leading to out-migration and population decline became common features of rural areas in all developed countries. It is against this background that the creation of new employment opportunities in rural areas has become a major focus of rural policy initiatives. From a human resources 
perspective, rural areas face a number of structural weaknesses from those of ageing demographic structure to the exodus of young people and skilled workers and a predominance of jobs in the type of work undergoing deep-reaching changes (OECD, 1995: 95).

In European social policy the primary emphasis is on employability and maximising labour resources that are available. Examples of these policies include early and systematic intervention programmes with unemployed people, which provide such people with the necessary skills to improve their employability. The Amsterdam Treaty includes an employment chapter relating to the condition of Member States' employment policies. For this purpose the European Commission draws up annual guidelines and the National Development Plans prepared by each Member State must take account of these guidelines. Included in the guidelines agreed for 1999 at the Vienna European Council in December 1998 are issues of improving youth unemployment and preventing long-term unemployment; promoting a labour market open to all; tackling gender gaps; reconciling work and family life and facilitating reintegration into the labour market. The national employment plan for Ireland (Employment Action Plan, 1998) includes policies and actions to promote a framework for lifelong learning which encourages individuals to access quality education and training on an ongoing basis and enterprises to invest in human resource development, to meet new and rapidly changing needs.

These are just a sample of the policies currently being pursued. They all however indicate that rural societies are continually being challenged, with the emergence of new needs, the reduced influence of agriculture and the development of a range of technologies in the areas of communication, transportation etc.; all of which are explicitly linked with development and employment opportunities. The growth in the Irish economy has not been felt in all areas of Ireland, particularly rural Ireland. While it is inevitable that changes will not impact uniformly across any given space, the continued and increasing disadvantage felt by many rural communities is in stark contrast to the rapid and sustained development in others. The recent Government white paper on rural development suggested that two of the more prevalent challenges facing rural areas were the increasing trend toward urbanisation through the growth of small urban centres and the continued decline in remote rural areas. While job creation and employment have increased nationally, rural areas are still disadvantaged in their ability to attract new investment opportunities. The Government subsequently committed, in this white paper, to ensuring vibrant sustainable rural communities; equity in terms of opportunity between rural and urban communities; sufficient income and employment opportunities, and access to education, training and adequate levels of social and other services and infrastructure. This commitment to "balanced regional development" and providing "employment opportunities to those in rural areas who have been less than active in the labour market" has little by the way of practical support mechanisms (see Department of Agriculture and Food, 1999). Further, the fact that Donegal is one of the counties that will retain Objective One status in the coming years is seen as the panacea for the future ills of the county. The argument is that it will be easier for Donegal to invest in infrastructure and to attract investment through its ability to grant-aid jobs to a greater extent than other counties outside the Objective One region. While this 'giving of grants' is a huge attraction it is not the only incentive which will attract and retain investors in the region, with investment in education and training being of far greater long-term importance. 


\section{The Study}

The substantive part of the paper reports the results of a large-scale survey of both 'official' and 'hidden' unemployed people in Donegal (excluding the Gaeltacht and the Inishowen Peninsula). Commissioned by Donegal Local Development Company the project was undertaken to understand better:

(a) the social, economic and educational characteristics of unemployed people;

(b) the perceptions and experiences of unemployed people;

(c) factors which hinder unemployed people from gaining work;

(d) the usefulness of official interventions in the labour market.

Such a survey was deemed necessary because Donegal at the time had the highest rate of long-term unemployment in the State (DLDC, 1996) with perceived high levels of further 'hidden' unemployment consisting of those available for work but discouraged from registering because of the lack of jobs. It is argued that this type of unemployment is now on the increase because greater joblessness has eroded the traditional divide between employment and unemployment (Metcalf, 1992). In high unemployment societies people may well become discouraged and withdraw from the official labour market. Indeed, it was felt highly probable that in Donegal there are many people who are not officially counted as unemployed but who would like work if given a viable choice and that these 'hidden' unemployed would be concentrated in specific groups such as young people, disabled people, and people (either men or women) who describe themselves as 'looking after the house'. O'Hara (1998) also recognised this in relation to the role of farm women in Ireland, their invisibility in official statistics and their under-representation when dealing with changing farm structure etc. in rural Ireland. As a consequence, the survey reported here questioned both registered and unregistered unemployed people in Donegal in order to acquire basic quantitative and qualitative information on local unemployment, both as an objective social phenomenon, and as it is experienced by local people, with a view to establishing more relevant and appropriate operational procedures, forms of intervention and supporting structures, based upon identified and perceived local need.

Since the survey was designed to generate different kinds of information, pertaining to the registered and unregistered unemployed, two different research instruments were constructed and differentially targeted in order to generate two distinct and separate data sets, based upon the distribution of two questionnaires. The first, aimed at both the registered unemployed and the hidden unemployed (see Green, 1997), was targeted through, and conducted by, a range of community organisations and groups. The choice of working with community groups was made for both practical and ideological reasons in that community involvement was considered the most effective way to contact the 'hidden unemployed' but also because community action was one way to empower local groups. The second, aimed specially at the registered unemployed, was conducted by the research team at local and district social welfare offices at those times when social welfare recipients came to 'sign-on'.

To a considerable extent the information sought within the context of both survey instruments overlapped but, where appropriate, information of particular relevance to each targeted group was also included. The first questionnaire (hereafter identified by the label 'Community Survey') was explicitly designed to elicit a range of information (see Table 1). The second questionnaire (identified from now on by the label 'Social Welfare Survey') 
differed from the first in that it included information on claimants' knowledge and use of benefits, allowances and social welfare office support facilities, and did not include questions related to the respondent's labour market situation or main source of income.

Table 1: Data sought by surveys.

Current and pre-unemployment geographical location

Age; Gender; Family composition and structure

Main source of family income

Economic activity of family members

Education; Post-school qualifications and training

Relevance of education and training in terms of labour market opportunities and outcomes

Labour market situation; Duration of unemployment

Pre-unemployment economic activity

Job-search activities, strategies and methods

Transport access and willingness to travel

Job aspirations and pay; Emigration

Individual perceptions of the causes of joblessness

Perceptions of the nature and structure of the local labour market, including employment

opportunities by district and an assessment of local employers in terms of wages and conditions

Involvement in and benefits of employment programmes and schemes;

Individual training and support needs;

Local and national employment generating initiatives and the ranking of Donegal develop-

mental needs.

The topics and questions included on the questionnaire were decided in a twofold way. First, in the standard manner, the literature was consulted to throw light on the types of issues which were appropriate for inclusion. Second, local organisations in Donegal were consulted on the design of the questionnaire, and on the sorts of questions which could be usefully included. In practice this meant that an iterative approach to questionnaire design was used as the work went through several stages of drafting and comments.

The nature and complexity of the information sought, and therefore of research instrumentation adopted, was such as to necessitate the use of direct one-to-one structured interview techniques. An awareness of likely difficulties accessing, in the time available, unregistered economically inactive people, coupled with a recognition of the value and importance of local participation, knowledge, local contacts, patterns of relationships and trust, encouraged the use of a collaborative approach involving the active participation of community groups and organisations whose activities regularly bring them into contact with unemployed people. Four organisations, each representing an identifiable and significant district within the study area, agreed to participate in and conduct that element of the survey aimed at both the registered unemployed and unregistered economically inactive. These were the ICTU Centre for the Unemployed, Letterkenny; Convoy Enterprises Ltd, Convoy; Erne Enterprises, Ballyshannon; the IRD (Integrated Resource Development), Milford. Questionnaires were distributed to each participating organisation and volunteers and group members were provided with such advice and training as felt necessary by members of each community sponsored survey team. The Convoy, Ballyshannon and Milford groups were 
contracted to undertake 100 interviews each, while the Letterkenny group agreed to undertake 200 interviews given the greater population density in the Letterkenny area.

Of an anticipated targeted response of 500 completed questionnaires, in all 469 were returned by participating groups. Difficulties accessing relevant population cohorts experienced by two of the four organisations were partially compensated for by the increased involvement of the ICTU in Letterkenny, whose members agreed to conduct an extra 40 interviews. In all, slightly more women than men were interviewed and 44.6 percent of respondents were under 25 years old. All the data were collected between May and October 1997.

The Social Welfare Survey also encountered some minor difficulties. The dispersed nature of much of Donegal's rural population means that many social welfare claimants sign at a number of district or local offices and many more at local Garda stations. Attendance at these offices and stations also takes place on a alphabetical rolling basis. It was necessary, therefore, in order to acquire an adequate geographical and generally representative sample, to disperse fieldworkers at different centres throughout the region and to canvass sites more than once. Interviews took place at social welfare offices in Letterkenny, Ballybofey, Ballyshannon and Donegal Town and at Garda stations in Raphoe, Convoy, Carrigans, Ramelton and Killybegs. The location of fieldworkers at signing points also generated some resistance on the part of potential respondents many of whom, in spite of assurances to the contrary, identified field staff with the social welfare system. The resulting response, in these circumstances, was a little lower than anticipated. In all 151 completed interviews took place at these sites.

Given the possible extent of 'hidden unemployment', it is difficult to make comments about statistical validity and reliability since, by definition, the population of 'hidden unemployment' is unknown. Moreover, given the complex social reality of unemployment, official data categories may not fully capture the nature of the phenomenon, particularly in an area of high unemployment. Despite these caveats, however, it was felt that the data collected represented the experience of unemployment, and perhaps captured information not usually present in standard analyses of claimant unemployment.

\section{The Results}

For purposes of discussion, the results have been divided into three related sections, labour market histories, education and training, and perceptions of the labour market. Where there are significant differences between the Community Survey and the Social Welfare Survey the data are presented separately but in other cases, where there are no interesting variations, the data have been merged.

\section{Labour market histories and experience of unemployment}

In this section, the duration of unemployment is examined together with information on job-search activities, transport and willingness to travel, job aspirations and pay, and individual perceptions of the causes of joblessness. In wider debates about unemployment these issues are significant. For example, it is often argued that unemployed people are not 'flexible' enough in the ways they seek work or the types of job that they require and that their 'reservation wage' (the minimum wage at which they will take a job) is unrealistically high therefore causing a situation where they are trapped in the benefit system. In the SFA 5 th National Employment Survey (1999) for example, as much as 41 percent of prospective employees sought to be paid 'off the books'. The Director of the SFA (cited in the Irish Times, 
$3^{\text {rd }}$ November 1998) suggested that 'the pervasiveness of the 'black economy' is such that employers often find it difficult to match the take-home pay of someone claiming social welfare and doing occasional work at the same time". However the Irish National Organisation of the Unemployed (INOU) disputed this perspective by suggesting that the myth of unemployed people not wanting to work is dispelled by the fact that 90 percent of the 72,000 jobs created in 1998 were taken up by the jobless. As such, the INOU argued that employers who were having problems filling vacancies should be investigating what they are doing wrong, rather than what is wrong with the unemployed (O'Sullivan, 1999, Irish Times, p.17).

Table 2 takes a first look at the data and shows how unemployed people assess their labour market position and how this accords with administrative definitions. This table suggests that there is no clear dichotomy between unemployment and employment. Some 13 percent of respondents, for example, are not registered as unemployed but state they are looking for work. There are important gender differences - women are much more likely to state they are 'looking after the home' than men and are so have a smaller proportion unemployed. A significant minority (about 40 percent) of respondents to both the Community and Social Welfare Surveys had been out of work more than two years (see Table 3 ). This was mainly a male phenomenon.

Table 2: Labour market status (percentage rates).

\begin{tabular}{lrrr}
\hline Status & Male & Female & All \\
\hline Registered unemployed (seeking work) & 57.7 & 36.8 & 45.7 \\
Registered unemployed (not seeking work) & 9.7 & 4.6 & 6.8 \\
Job arranged & 6.1 & 6.1 & 6.1 \\
Scheme arranged & 4.1 & 2.7 & 3.3 \\
At home & 2.0 & 26.8 & 16.2 \\
Non-registered seeking work & 13.3 & 13.8 & 13.6 \\
Non-registered not seeking work & 6.6 & 0.2 & 8.1 \\
Going back to education & 0.5 & 0.0 & 0.2 \\
\hline
\end{tabular}

Source: Community survey.

Table 3: Unemployment duration (percentage distribution).

\begin{tabular}{lccc}
\hline Duration & Community Survey & Social Welfare Survey & Total survey \\
\hline Less than 6 months & 26.8 & 24.0 & 26.1 \\
6-12 months & 15.2 & 20.7 & 16.6 \\
1-2 years & 13.0 & 14.7 & 13.4 \\
More than 2 years & 45.0 & 40.7 & 43.9 \\
\hline
\end{tabular}

Source: CSO; Community survey; Social Welfare survey.

Income is a sensitive topic in any research of this type. The Community Survey asked questions about other sources of income and a majority (62 percent) of respondents said they were reliant on social welfare payments. In the Social Welfare Survey, about 60 percent of respondents were in receipt of Unemployment Assistance and this indicated that most had not 
had sufficient work in the past 24 months to entitle them to Unemployment Benefit. Respondents were also asked to indicate the minimum net wage they would expect to earn (given their qualifications and experience). This was considered an issue because Donegal is a low-wage economy and low wages are seen as a cause of unemployment because it is not economic to take jobs (Dawes, 1993). The mean wages were $£ 171$ for men (modal $£ 200$ ) and $£ 150$ for women.

Job-search activity and transport are issues of theoretical and practical interest. It is known that job search declines with duration of unemployment (Murphy and Armstrong, 1994). This is one reason why the odds of leaving unemployment decrease the longer someone is out of work. To look at this issue, the surveys asked if someone had looked for a job in the past month. A majority - 55 percent of the Community Survey and 71 percent of the Social Welfare respondents - had actively sought work. In general, respondents rated personal contacts, informal networks and adverts in shops as the best ways to find work (see Table 4). This suggests a greater role for official job placement measures. However, although unemployed people had sought work, only 35 percent of respondents had access to public transport. Despite this, there was little evidence that unemployed people were inflexible most said they would be prepared work part time and travel over 5 miles $(8 \mathrm{Km})$ to get to work.

Table 4: Job-search methods (percentage rates).

\begin{tabular}{lc}
\hline Method & Percentage \\
\hline Local paper & 29.0 \\
Personal contacts & 22.5 \\
Adverts in shops etc. & 10.6 \\
Agency & 4.1 \\
Job Centre & 10.4 \\
Other informal networks & 23.4 \\
\hline
\end{tabular}

Source: Community survey; Social Welfare survey.

Table 5: Perceived reasons for being unemployed (percentage rates).

\begin{tabular}{lc}
\hline Reason & Percentage \\
\hline Wrong skills & 19.9 \\
Too old & 8.6 \\
Too young & 4.1 \\
No jobs for men & 7.3 \\
No jobs for women & 5.4 \\
No experience & 18.1 \\
History of unemployment & 5.3 \\
Wrong area & 12.8 \\
No qualifications & 15.9 \\
Unwilling to work & 2.8 \\
\hline
\end{tabular}

Source: Community survey; Social Welfare survey. 
About 30 percent of respondents to both surveys had turned down a job. The leading reason for this was low wages, followed by perceptions that the work was poor quality, lack of transport, and perceived job insecurity. There were differences by gender. For women childcare was an issue whereas men rated insecurity higher. Respondents were also asked to evaluate why they were not in work (see Table 5). Responses revealed that supply-side issues such as wrong skills, no experience, and a lack of qualifications were important. Women tended to feel that they lacked skills but men felt that a history of unemployment, a lack of qualifications and a shortage of local jobs were particularly important.

\section{Education and training}

Education and training are significant because of the factors identified by survey respondents as causes of their unemployment. They are also important topics because of policies which stressed education and training as the means to equip unemployed people with the human capital needed to compete in a restructured labour market.

The importance attached to education is perhaps not misplaced. About 50 percent of respondents to both the Community and Social Welfare Surveys had left school before the age of sixteen (see Table 6). A substantial minority had gained no qualifications at school (about a third in total). There were some differences by gender since women left school later than men and performed better also. Age was also important as the share of respondents with no school qualifications rose for older age groups (see Table 7).

Table 6: Educational qualifications (percentage rates).

\begin{tabular}{lccr}
\hline Duration & Community Survey & Social Welfare Survey & Total survey \\
\hline None & 25.8 & 52.0 & 32.2 \\
Vocational & 6.5 & 2.7 & 5.6 \\
Intermediate Certificate & 15.0 & 20.3 & 16.3 \\
Leaving Certificate & 51.4 & 22.3 & 44.3 \\
O Levels & 0.2 & 1.4 & 0.5 \\
A Levels & 1.1 & - & 0.8 \\
Group Certificate & - & 0.7 & 0.2 \\
CSEs & - & 0.7 & 0.2 \\
\hline
\end{tabular}

Source: Community survey; Social Welfare survey.

About a third of respondents to both surveys gained post-school qualifications. These were very diverse and hard to code but included a wide variety of business, vocational and word-processing subjects. Leading providers in order of importance were universities, FẢS, on-the job training, and RTCs (now Institutes of Technology). The majority of respondents felt these qualifications were relevant to the labour market but men had greater access to training than women suggesting a gender gap. About 60 percent of respondents felt the need for more training to get work and the most commonly cited requirements were for information technology training and for college education. 
Table 7: Qualifications by age (percentage rates).

\begin{tabular}{lrrrrc}
\hline Zualification & $16-25$ & $26-35$ & $36-45$ & $46-55$ & $56-65$ \\
\hline Jone & 18.5 & 29.9 & 42.6 & 74.5 & 71.4 \\
Jocational & 6.3 & 3.0 & 6.6 & 4.3 & 21.4 \\
ntermediate Certificate & 15.0 & 21.0 & 17.2 & 8.5 & - \\
eaving Certificate & 59.4 & 44.3 & 29.5 & 12.8 & 7.1 \\
J Levels & 0.4 & 0.6 & 0.8 & - & - \\
\ Levels & 0.4 & 0.6 & 2.5 & - & - \\
jroup Certificate & - & 0.6 & - & - & - \\
SEs & - & - & 0.8 & - & - \\
\hline
\end{tabular}

ource: Community survey; Social Welfare survey.

\section{'erceptions of the labour market}

It is worthwhile to comment on labour market perceptions so that the needs of nemployed people can be understood in more detail as well as the constraints they might ace. In general, a majority of respondents ( 80 percent) to both surveys felt that it was not asy to get work in Donegal and also difficult to find work outside the county. But there are ome jobs, and it is worthwhile to find out whom unemployed people think these jobs are for. is Table 8 reveals, these perceptions indicate some duality in the labour market in that the zading group for whom jobs were seen as for were professionals - cited by 23 percent of espondents - but the next group was part-time workers identified by 18 percent of survey espondents, Following this, manual work and jobs for young people were seen as important.

able 8: Who are jobs for in the local labour market? (percentage rates)

\begin{tabular}{lc}
\hline Method & Percentage \\
\hline Men & 7.0 \\
Women & 5.9 \\
Young people & 14.5 \\
Old people & 1.6 \\
Professionals & 22.8 \\
Manual workers & 15.2 \\
Unskilled & 4.8 \\
Urban workers & 9.6 \\
Rural workers & 0.9 \\
Part-time workers & 17.7 \\
\hline
\end{tabular}

ource: Community survey; Social Welfare survey.

Respondents were also asked to rank the 'best' employers and the 'best' places to find ork. There were many responses making these data hard to code. The major employers icluded Fruit of the Loom and the leading sectors for the best jobs were manufacturing, cited y 45 percent of respondents, followed by public services ( 23 percent) and private services 
(10 percent). Towns were seen as the best locations to get work thus indicating some problems for rural residents. This perception, however, is at variance with the research of Murphy (1996) which suggests that unemployment in lreland is mainly an urban phenomenon.

\section{Discussion}

These findings, and the findings of other studies such as A Study of the Donegal Economy, 1996 and Survey of Employers 'Skills Requirements, 1996, clearly indicate that unemployed people in Donegal are not benefiting from the 'Celtic Tiger' phenomenon. The perceptions that unemployed people have of the local labour market is one of polarisation the leading categories for whom jobs are identified as being for are professionals and parttime workers. In either case many of the registered and hidden unemployed people surveyed in our study would probably find it problematic to gain work. In the case of professional jobs, a substantial proportion of people have no qualifications and are thus unlikely to be able to gain this type of employment. In the instance of part-time work, low wages, the operation of the benefit system, and the type of work on offer, are likely to be disincentives for unemployed people (particularly for registered unemployed men). The extent of social exclusion that is being generated is shown by the substantial minorities (over 40 percent) who have been without work for more than two years and the majority (over 55 percent) who have had no job for more than one year. The Donegal regional economy as a whole has not benefited from the economic growth of the 'Celtic Tiger' - and at the same time there are substantial proportions of jobless people who see problems in re-entering work, and getting the jobs that exist, because they perceive themselves as lacking experience, skills, work history, and because they see the available jobs as unsuitable in various ways. In this context the whole area of rural development policy with its stated aim of providing a "comprehensive and all embracing education system...on a geographically dispersed basis" and providing "sufficient income and employment opportunities" in rural areas (Department of Agriculture and Food, 1999) must be questioned.

These are macro-level issues, reflecting the nature of economic change in Ireland. Given the results, and Donegal's position within the space-economy, particularly in relation to the 'Celtic Tiger' phenomenon, it seems that there are a number of micro-level locally-based initiatives that can significantly impact upon areas of policy. These extend beyond the operation of the benefits system as it affects unemployed people and the low demand for labour in Donegal, which are within the remit of central Government. The first measure is to improve the provision of information about benefits for unemployed people, including the various schemes and incentives to help unemployed people into work. At present, informal methods of job search are the most frequently used and the most effective. Few respondents to the surveys had heard of job facilitators, let alone met one. This suggests that there are problems in the functioning of existing measures in that they are not affecting unemployed people, or at the very least improving their material conditions even if not helping them directly to get jobs. One solution to this would be the establishment of closer links between Social Welfare, agencies such as DLDC, job facilitators and community groups in order to foster relationships between agencies and job seekers.

The second measure is to target interventions spatially. Just as there are differences between Donegal and the rest of the State which make local interventions desirable, so there are considerable differences within Donegal. Urban areas, for example, are perceived as 
having better job opportunities and having fewer transport problems. In contrast, more rural areas have greater problems of accessibility and in some cases greater experience of unemployment. This suggests that policies should be tailored to suit the needs of localities. Transport might be, for example, stressed in rural areas and discretion might also be needed in encouraging investment and employment. In towns, on the other hand, there might be a greater need to provide training facilities to help unemployed people gain jobs that are already there.

The third measure is to improve access to employment. In general, unemployed people felt that they could not gain access to employment. Reasons given included the operation of the benefit system, transport, training and childcare. Some problems, such as those of the benefit system, are beyond the remit of local agencies. However, the issues of transport, childcare, and training probably can be usefully addressed locally. Transport in particular is a major problem. Unemployed people seem prepared to travel to find work. However, many of them lack the means of transport to get to work even if any were available. These problems of access are pronounced in Donegal where poor public transport exacerbates problems. Community-based transport initiatives might be a way to reduce these problems and to take things forward.

Childcare was observed to be a problem, particularly for women, in both the surveys. Female employment has expanded markedly in most advanced economies, particularly in the part-time and temporary sectors (Hanson and Pratt, 1995). This suggests that there is a need for childcare which is flexible both in nature and cost. The growth of non-traditional types of family is also a trend that is worthwhile considering as single parents may well lack the resources (e.g. easy access to a partner or grandparent) to ensure children are cared for if the parent goes out to work.

Questions of accessibility are also particularly important when the analysis is extended to include considerations of the concentration of unemployment in certain households and the importance of informal networks in gaining jobs. These features have been well rehearsed in other countries and regions but there has been little discussion of the their impact upon local economic policies. In effect, these developments mean that certain individuals and households are isolated from the labour market and information about jobs. Any jobs that are going in the locality, therefore, will tend to go to the better-off. This is an issue that could be addressed by local agencies in terms of the provision of information and by the identification of jobless households whose sole income comes from social welfare. If opportunities can be directed at this type of household, this type of social exclusion could be reduced.

Most unemployed people contacted seemed satisfied with the education and training schemes that were already in place, except that they wanted more education and training in general. There are some issues which should be considered when discussing these related themes. First is that of age. Poor qualifications and a lack of education/training opportunities are greater problems for the older unemployed. In many cases, people past the age of 40 lack the educational/training background to take advantage of any opportunities that exist. This means that training/education provision should not be expanded indiscriminately but should, perhaps, be concentrated disproportionately on skilling older unemployed people. Second is the question of the types of training that are required. Many types of training could be irrelevant to the needs of the local labout market and therefore to unemployed people. Training as a general concept may therefore have little applied value as specific types of 
training in specific areas might be needed. In evaluating the types of training needed questions should be asked about the kind of labour market for which unemployed people are being prepared. Unemployed people themselves perceive the labour market as being polarised with opportunities for both professionals and for part-time workers. Any education and training strategy needs to decide which of these niches is the one for which unemployed people are being trained. A choice of the part-time route implies a low-skill strategy for the local economy. A choice of training to fit unemployed people to take advantage of high-skill and presumably higher-wage professional jobs means a greater investment in training and greater expansion of training facilities.

The last measure is to make sure that consideration is directed to specific sub-groups of the population. One fundamental decision is whether local agencies should just seek to address the problem of the registered unemployed or whether there is a broader remit to deal with the social exclusion of the hidden unemployed as well. The basis on which this decision will probably be made is on the choice of performance indicators (for example, a reduction of registered unemployment versus broader concerns with social inclusion). At a less basic level, the experience and needs of women and disabled people are very different from those of men and able-bodied people, and the experience of unemployment in urban areas is different from that of the country. These considerations mean that unemployed people are not an easily-defined and homogenous population but are instead heterogeneous with differing requirements. A local policy to reduce unemployment will therefore probably not consist of one or two main strands but will be very likely to have several 'faces' which it presents to various groups of unemployed people. Of course, there will have to be consistent themes for example access and training - but the modes of delivery of measures to address these themes will vary.

At a more speculative level, there are also sub-groups of the population which might also require assistance. In the study, disabled people and early school-leavers were identified as being two such groups (see Kitchin et al.,1998). Very little is known about these groups and indeed, given their 'hidden' nature and the ways in which these groups of the population are ignored by official data, it may be impossible to quantify their extent exactly. However, more research into these, and similar groups, might be necessary. Particularly effective, given the cumulative nature of labour market disadvantage, could be policies directed toward young people. Careers advice and community-based support for schools could be useful ways to develop the work of local agencies such as the DLDC and might act to limit the costs of later labour market disadvantage and unemployment.

\section{Conclusions}

Some findings have been presented in this paper from a large scale survey of unemployed people in Donegal. The analysis suggests that unemployment in Donegal is a complex phenomenon because it exists outside official data categories. About 58 percent of men in the Community Survey, for example, stated they were registered unemployed but this left a substantial minority whose labour market status was more ambiguous. For women, moreover, hidden unemployment was more likely to be pronounced - only about 37 percent of women who classed themselves as unemployed in some way were actually registered as unemployed. This indicates not only gender differences in the experience of unemployment and the need for gender-specific policies but also the likelihood that administrative attempts to measure unemployment are likely to underestimate its social prevalence. 
The results are also interesting in the extent to which joblessness is shown to be long term. This experience, together with the problems that young people face in finding stable work, might lead to a permanently socially excluded sub-section of the population. These jobless people have not benefited from the 'Celtic Tiger'. In wider terms, the labour market is perceived as offering a polarised alternative of jobs for professionals or for part-time workers but jobless people see themselves as having the wrong skills and experience to get work. To some extent, this perception might not be misplaced because of the proportion of jobless with no qualifications and for these people education and training might offer a way forward. This is a perception that a majority hold themselves.

Some local issues are also of importance. Access to transport was mentioned as a factor in leading to joblessness and this was a factor, indeed, that had led some to decline a job offer. The value of widening channels of information in the labour market was also apparent since many respondents said they had used personal contacts, informal networks (i.e. word of mouth), and adverts in shops, as the main means by which they had looked for work. These approaches may be effective. However, they are also likely to be spatially restricted and mean that someone using these local channels of information will be unaware of opportunities outside quite a small area. Combined with transport problems, it is likely that these information flows act to disadvantage residents of remote and rural areas.

The final theme that arises from the analysis is the requirement to tailor policy interventions for specific sub-groups of jobless people. Jobless people are not homogenous in terms of their social characteristics or their needs. Instead they are heterogeneous. Women, for instance, face different obstacles than men in gaining work. There is also an age dimension which means that older jobless people face a lack of provision of support, and that their problems (often of a lack of work experience), differ from younger people who may have missed out on schooling or who come from socially-disadvantaged families. This implies the need to create an overall policy framework to attack unemployment and poverty, but also a need to include targeted measures for specific groups, such as disabled or young people, thereby recognising the social diversity of joblessness.

These overall points also apply in geographical terms at several different spatial scales. Firstly, the regional context of unemployment usually varies in any society as a function of local labour market conditions. Area-based strategies are therefore an important focus for tackling disadvantaged groups. That is, the background to joblessness, for example, is different in Dublin to what it is Kerry or Donegal suggesting the importance of place-specific variation in its causes, nature and cure. In Donegal, low levels of job creation, rural de-industrialisation, and rurality, set the context for long-term joblessness. To cope with these regional variations, it is probably necessary to deliver policy at regional levels within a centrally-set administrative framework to ensure inter-regional equity. To this end the success/ability of the new Regional Assembly and the retaining of Objective One status in the west and border counties will be significant in counteracting issues of disadvantage and unemployment in places like Donegal. The concept of local development companies and partnerships as a way of increasing the input of local communities in decision-making and in policy formulation and delivery is subsequently gaining currency. This type of local accountability could give more 'ownership' of their destiny to jobless people. Secondly, there are more local variations in labour markets and experiences of joblessness within regions to which policymakers might consider. In Donegal, for instance, it would be an oversimplification to imagine that all problems of joblessness are a consequence of rurality and peripherality. In Letterkenny, the expe- 
rience of unemployment has something in common with other urban areas but in smaller towns, and the more rural parts of the study area, accessibility and transport are much more likely to be issues. In some villages, formerly dominated by a single, now-gone large employ$\mathrm{er}$, rural de-industrialisation is significant. Therefore, even at this intra-regional spatial scale, place-specific factors are important since they create distinct local geographies of labour market opportunity. A word of caution must be voiced however. The growing acceptance of collective community action and the increase in 'partnerships' (that is, local communities; voluntary bodies; Government agencies) as being able to tailor activities to the local problems they encounter will require a great deal of political goodwill and commitment (McDonagh, 2000). Further, local community groups or partnerships cannot have foisted on their shoulders responsibility for solving what are essentially macro-scale problems. However, while it would probably be too much of an administrative overhead to take the multiplicity of local considerations into account when planning policy formulation and delivery, nevertheless, policymakers could be more sensitive to these issues as they are themes which loom relatively large in the worldviews of jobless people and of community representatives.

Overall, then, in summary, the paper argues for a more diversified approach to joblessness and the strengthening of local initiatives and approaches. This would recognise the social heterogeneity of jobless people and also the importance of place-specific factors in shaping local labour markets. National policies are, of course, necessary but their impact could be limited because of local circumstances, and it is likely that measures that are appropriate for one part of the State may well be less appropriate elsewhere. Decentralisation of service provision for jobless people could thus usefully be encouraged.

\section{Notes}

This study was funded by Donegal Local Development Company as part of the 'Contact Programme with Unemployed People' project funded by the Operational Programme for Local and Urban Rural Development.

\section{References}

CURTIN, C., HAASE, T., and TOVEY, H. (eds) (1996) Poverty in Rural Ireland: A Political Economy Perspective. Dublin: Combat Poverty Agency.

DAWES, L. (1993) Long-Term Unemployment and Labour Market Flexibility. University of Leicester: Centre for Labour Market Studies.

DEPARTMENT of AGRICULTURE and FOOD (1999) A Strategy for Rural Development in Ireland a white paper on Rural Development. Dublin: Government Publications.

DONEGAL COUNTY ENTERPRISE BOARD (1996) A Study of the Donegal Economy: Facts. Figures and Analysis. Letterkenny: Donegal County Enterprise Board.

DONEGAL LOCAL DEVELOPMENT COMPANY (1996) Survey of Employers ' Skill Requirements. DLDC.

COMMISSION OF THE EUROPEAN COMMUNITIES (1988) The Future of Rural Society. Brussels: Commission of the European Communities.

GREEN. A. (1997) Exclusion, unemployment, and non-employment, Regional Studies, 31, 505-520.

HANSON, S. and PRATT, G. (1995) Gender: Work and Space, London: Routledge.

KITCHIN, R.M., SHIRLOW, P. and SHUTTLEWORTH, I. (1998) On the margins: Disabled people's access to and experiences of employment in Donegal, West Ireland, Disability and Society, 13, 785-806.

LETTERKENNY RTC (1997) Survey of Employers 'Skills Requirements. Letterkenny: DLDC.

LEYSHON, A. and THRIFT, N. (1997) Money/Space. London: Routledge. 
MacGRÉIL, M. (1998) Quo Vadimus, Cá bhfuil àr dtriall? Where are we going? Report on the Pastoral Needs and Resources of the Archdiocese of Tuam. Galway: Archdiocese of Tuam.

McDONAGH, J. (2000) Partnership and Integrated Rural Development in Ireland, Administration, Forthcoming.

METCALF, H. (1992) Hidden unemployment and the labour market, In: McLaughlin, E. (ed.) Understanding Unemployment. London: Routledge.

MURPHY, A. (1996) The incidence of male unemployment in Ireland, Economic and Social Review, $25,467-490$.

MURPHY, A. and ARMSTRONG, D. (1994) A Picture of the Catholic and Protestant Male Unemployed. Belfast: Central Community Relations Unit Employment Equality Review Research Report 2.

NESC (1994) New Approaches to Rural Development. Report No. 97. Dublin: NESC.

OECD (1995) Creating Employment for Rural Development. Paris: OECD.

O'HARA, P. (1998) Pariners in Production? Women, Farm and Family in Ireland. New York, Oxford: Berghahn Books.

O'SULLIVAN, J. (1999) Labour shortage threatens to cripple the economic boom, Irish Times $14^{\text {th }}$ May 1999.

SFA (1999) Small Firms Association Fifth National Employment Survey 1999. Dublin: SFA.

SHIRLOW, P. (1995) Contemporary Development Issues in Ireland, In: Shirlow. P. (ed.) Development Ireland: Contemporary lssues. London: Pluto Press, 1-14.

SHIRLOW, P. (1996) Transnational Corporations and the Illusions of Economic well-being, Regional Studies, 29, 687-691.

SHUTTLEWORTH, I., SHIRLOW, P. and McKINSTRY, D. (1996) Vacancies, access to employment and the unemployed: two case studies of Belfast and Londonderry, In: McLaughlin, E. and Quirk, P. (eds) Policy Aspects of Employment Equality in Northern Ireland. Belfast: SACHR, 27-50. 